\title{
APRENDIZAGEM SOBRE 0 APRENDER: 0 FIO DA SINTONIA
}

Rachel Lea Rosenberg 
O ensino tradicional tornou-se incoerente para o mundo de hoje. No entanto, as propostas renovadoras para a Educação ainda não parecem ter estabelecido sua plena validade, e os resultados de muitas experiências inovadoras têm se mostrado tão. insatisfatórios quando não catastróficos - que neste campo prevalecem a confusão e o retrocesso. E o momento de retomarmos algumas perguntas antigas, para as quais as nossas respostas óbvias podem ter nos desencaminhado. Qual o papel da escola, da Ciência, do cientista, do educador? Quais suas relações com a Arte, a sabedoria e a competência do viver humano?

Voltada para uma busca pessoal de um dia entender melhor tais questões, proponho-me a um exercício de reflexão, envolvendo algumas aprendizagens sobre a aprendizagem, tal como a tenho experimentado e observado. Como parte introdutória, quero recortar e apresentar aqui comentários-fragmento que tocam, clareiam, envolvem minhas dúvidas.

Sobre a sociedade e as ciências do comportamento:

Vejamos como diligência e boa vontade podem ser ineptas. Nas ciências sociais e nas profissões de ajuda, a maioria de nós se imbui do desejo bem-intencionado de aplicar à realidade social as lições de nossa formação e prática. Preocupamo-nos com o indivíduo e o mundo, com seu bem-estar, seu pleno desenvolvimento e sua sobrevivência dignificante. Enquanto educadores, temos considerado nobre a nọssa missão de oferecer um subsídio à evolução humana - não obstante tal conceito variar enormemente! $E$ enquanto acadêmicos $e$ pesquisadores, dedicamos os maiores esforços a encontrar soluções para os problemas e deficiências que afligem os seres humanos. Neste sentido, os cientistas nas áreas humanas tradicionalmente encaram a sociedade como um "receptor" ou "aprendiz", mesmo que relutante, mas paradoxalmente, a sociedade tende a considerar as ciências humanas como "espectadoras" passivas, inócuas, afastadas.

Então, apesar da segurança complacente de estudiosos e educadores, a Educação está à cata de novos caminhos, alertada para sua própria ineficácia ou, pior ainda, para seus efeitos não-explícitos e possivelmente nefastos. Num extremo radical de pensamento, Illich, por exemplo, denuncia a escola de hoje como "o principal fator na 
criação da pobreza (de propriedade, poder e influência) nas sociedades modernas e em modernização, ou seja, em todo lugar" (1971, p. 3). Usando de terminologia mais moderna, o psicólogo norte-americano Carl Rogers expõe sua convicção de que "a falta de um meio humanista [facilitador] age contra a aprendizagem [ tanto pessoal como pessoalmente construtival" (1985, p. 181). Aliás, raros entre nós - em qualquer pólo - a negar que hoje a maioria das interações em sala de aula ou das experiências escolares dá lugar à insatisfação!

De fato, em toda parte os estudantes manifestam sua insatisfação. Na América Latina, onde uma instrução superior constitui em si mesma um privilégio para poucos, poder-se-ia supor uma postura menos crítica. Temos, pelo contrário, comprovações repetidas de que nossas universidades estão muito abaixo dos padrões discentes de excelência. Moreno, por exemplo, descreve o mal-estar de numerosos estudantes mexicanos diante de suas faculdades (1979). E como em toda a América Latina, no Brasil se testemunha a discrepância considerável entre os propósitos da Educação e seus resultados. Se em todo o mundo a escola e a Educação sofrem duras críticas, a proposta da educação humanística não representa uma exceção clara neste quadro de fracassos. Em termos de contribuir com métodos mais sintonizados às necessidades de solução de problemas humanos, Wood parece-nos justificado em afirmar que " de modo geral, movimentos [da psicologia humanística] ainda estão longe de produzir um aumento notável nas capacidades de resolver problemas humanos vitais" (1982, p. 22).

Os autores interessados em Educação Humanista apontam para diversas causas e curas da situação atual. Peretti, conceituado acadêmico francês, nos propõe: "A relação entre os conhecimentos, e o saber-fazer e o saber-ser, não cessa ela mesma de de complexificar, para os grupos como para cada indivíduo. Todos estão ao mesmo tempo ávidos de conhecimento e formação, mas também nauseados pela avalanche de idéias e pela obsolescência de expressões ou formas" (1972, p. 203). Uma conclusão menos original, por ser hoje de consenso, é a que nos vem de Pretto, pesquisadora brasileira: "As queixas dos estudantes têm um ponto em comum: a professora e suas atitudes para com seus estudantes" (1978, p. 3). E sua conclusão preludia um alerta: "[A professora]poderá contribuir ao crescimento pessoal $\mathrm{e}$ intelectual do estudante na medida em que ela 
própria for uma pessoa em constante crescimento" (p. 4). Distante milhares de quilômetros, o francês Filloux escreve: "Se admitimos que a prática educativa é a prática de uma relação humana, aparece como exigência não poupar uma formação pessoal, ou seja, uma interrogação pessoal sobre si mesmo, sobre os desejos de poder, sobre o domínio que necessariamente cada um de nós exibe" (1983).

De um ângulo alternativo, mostram-se fatores sociais e econômicos, ao lado da força política, como determinantes e mantenedores de um sistema hierárquico rígido de reificação e conformismo, que decerto imprime marcas na forma e na estrutura educacionais.

No movimento humanista, Maslow por sua vez preconiza qual deveria ser o ideal na Educação: "De um lado. desvendar ou descobrir a sua idiossincrasia, o modo pelo qual você é diferente de todos os outros seres no mundo inteiro. E além disso, por outro lado, descobrir-se da espécie, do humano" (1971, p. 187). No seu entender, as necessidades do aprendiz seriam satisfeitas por um tipo "intrínseco" de aprendizagem que levaria ao encontro da sua identidade e sua vocação.

Destes exemplos, se deduz uma variada gama de sugestões quanto ao que deverá mudar, se de fato se deseja melhorar o ensino. Quando a meta é a habilitação de educadores, ou facilitadores de grupo para uma ação centrada na pessoa - e não um programa centrado num currículo, num sistema de normas ou num fim político -, os procedimentos deverão ser congruentes com as políticas e os métodos que recomendamos para a Educação em geral. Da amostra apresentada aqui, e que acredito representativa, deduz-se que na busca de renovação será preciso passar por roteiros diversos, que incluem as atitudes dos professores, as contingências sociais e políticas, o nível de facilitação da sala de aula, o clima psicológico da escola, os métodos didáticos, o autoconhecimento tanto do educador como do educando.

Se nós, educadores e cientistas, nos propomos a oferecer serviços mais profícuos à sociedade que nos envolve, é importante que cuidemos de nossa própria saúde. A maior parte das soluções sugeridas se origina das ciências elas mesmas, da Economia à Psicologia, da Pedagogia à Ciência Política, com todos seus viezes. Triste é admiti-lo, as respostas da Ciência ao ceticismo do mundo "lá fora" têm se revestido de persuasão, obscurantismo, esnobismo e autopro- 
moção. Em termos de classe e de indivíduos, nós, cientistas do social, com freqüência temos zombado do senso comum, obtido a última palavra tornando-a a mais incompreensivel, nos vangloriando de nossa omnisciência, menosprezando os sentimentos das pessoas.

Neste contexto, uma Abordagem Centrada na Pessoa e no seu poder pessoal, uma visão confiante na capacidade humana de autodireção individual e grupal, no sentido do pleno crescimento, se firmam como base para drasticamente reverter a situação atual da relação entre as ciências do comportamento e a sociedade de pessoas. Em Psicologia e outros campos de estudo das relações humanas, encontramos autores que se detêm para ouvir diretamente às pessoas, tal como vivem, experimentam, crescem, pensam, sofrem e criam o significado e a expressão de quem elas são e querem vir a ser. Esta é, portanto, uma nova maneira de encarar a dissonância entre as pessoas capacitadas e leigas, ou o impasse na Educação. Ter como diretriz tal Abordagem, que privilegia cada pessoa como fonte de autociência, jmplica num canal recíproco de comunicação entre pares de grupos de experiências artificialmente separadas e fechadas, metaforicamente os das "autoridades" e os das "massas" A Medicina, a Pedagogia, a Administração e a Psicologia têm negado por tempo demasiado o caráter único da vida pessoal. Cada uma destas áreas empreendeu longas séries de batalhas para assegurar sua autoridade sobre a Pessoa, detalhando longas e sucessivas cartas de verdades absolutas que se mantêm por algum tempo, são submersas por outras verdades igualmente absolutas e igualmente afastadas da vivência real e única. Numa Abordagem Centrada na Pessoa, haveria uma convergência de conhecimentos, ao invés das "vitórias" partidárias.

Como já se provou muitas vezes, problemas causados por uma dada tecnologia não podem ser sanados pelos mesmos campos de referência - ou seja, os males causados por certos medicamentos, pela aceleração industrial ou pela tecnocracia do ensino não poderão em última instância ser compensados por recursos de igual teor $O$ fato é lógico, e desconsiderado com facilidade, talvez por conveniência, ou quem sabe por uma atitude de soberba. A metodologia essencialmente centrada na pessoa (Rogers, 1985) ilustra como se pode receber uma contribuição nova, "de fora" à ciência do humano, uma volta ao próprio humano como fonte de e para mudança. Subrepticiamente, tal força pessoal se impõe no social, onde e como 
pode fazê-lo. Os estabelecimentos para a aprendizagem sempre tiveram suas fendas, através das quais podia entrar o sopro da vida plena. Ao lado do poder institucionalizado de docentes e administradores, o poder complementar oposto, vindo de dentro pelos alunos e de fora pelos acontecimentos sociais, tem desempenhado um papel influente. Além disso, através de convênios, subvenções e financiamentos, a pesquisa e a formação sạ̃o em parte controladas pelas forças econômicas e governamentais, sendo o primeiro caso característico na América do Norte e o último muito comum na América Latina. Em graus variados, trata-se de pressões que subvertem a rígida autoridade exercida pelo sistema estabelecido, admitindo a presença da vida social.

O fenômeno decerto não é exclusivo de instituições escolares. É curioso ler o comentário do cientista nuclear Dyson sobre a conduta dos comandantes britânicos na Segunda Guerra Mundial: "Em todo estabelecimento militar, podem-se encontrar homens que executam ordens sem eficiência excessiva, e que silenciosamente amenizam males que não podem desfazer" (1984, p. 57). Note-se que os atos desses indivíduos não seriam tidos por seus superiores como uma colaboração equilibradora, e sim como clara sabotagem!

Onde essas várias formas de interação com a sociedade são identificadas, reconhecidas, a tendência é rechaçá-las antes que acolhêlas, pois de fato acarretam uma restrição no exercício do poder por parte de pessoas ou grupos que dominam pela força ou pela convicção de seu direito. Desta forma, um terreno de desconfiança mútua gera o conflito permanente, empobrecedor, das alternativas mutuamente exclusivas. Uma Abordagem mais aberta à contribuição de todas as pessoas envolvidas talvez não "resolva" este conflito; mas propõe-se a estender a legitimidade de todo o espaço disponível aos dois lados da disputa, sejam eles a Ciência e a vida, a escola e a sociedade, os peritos e os consulentes, ou os educandos e educadores. Substitui a presente necessidade de hierarquias e categorias apriorísticas por um quadro mais flexível em que a melhor aprendizagem de cada um é de, ou com, os outros, e assim toda pessoa é plenamente valorizada. 
Sobre ideologia, tecnologia e Ciência:

Seria desonesto atribuir a qualquer autor os méritos únicos de descobridor da verdade. Mesmo que muitos psicólogos pareçam ainda atolados na década dos trinta, outros têm reconhecido agudamente a inerente interferência da ideologia no desenvolvimento da Ciência, assim como a desmedida das aplicações das teorias ao nível da prática. Bleger, perceptivo pensador argentino, fez uma distinção clara entre a Ciência psicanalíticả e o divã da realidade, e via a superposição de ambos como inibidora da investigação: é como quando "se procura o conhecido, de modo conhecido, e nunca se tenta alcançar o que é desconhecido" (1971, p. 122). Acrescentava, ainda: "Em campo algum, uma teoria se refere apenas aos dados de seu próprio campo, ou é deduzida tão-somente de dados comprovados. Encontram-se valores ideológicos e políticos que sustentam alguns dos critérios que implicitamente influenciam teoria e técnica: na psicanálise isto resulta claramente nos critérios para a saúde e a doença, a cura, a normalidade, etc." (p. 128). Bleger denuncia o controle oculto exercido por forças alheias ao campo teórico, e alerta quanto ao perigo da mera "aplicação" direta de constructos. O reconhecimento de influências e distorções ideológicas está presente igualmente na descrição que Maslow faz do ideal da Educação superior. Ao mesmo tempo em que propõe um modelo acadêmico coerente com o existencialismo, isento de créditos e títulos, lamenta a influência dos existencialistas europeus, que consideram o "homem como projeto inteiramente de si mesmo, inteira e meramente um produto de sua própria vontade arbitrária" (1971, p. 186).

Onde Bleger anseia por um modelo de Ciência mais adaptado à natureza humana do que os das ciências exatas ou naturais, Maslow propõe maior atendimento aos valores e à criatividade. No entanto, seria preciso descrever como a transformação desejada poderia ocorrer, exceto pela força ou pelo acaso, e é onde esses autores deixam uma lacuna. Sua contribuição nos alerta para a mudança, não nos instrumentaliza para ela. A proposta de Rogers se relaciona mais às condições concretas da Educação, e é portanto mais útil em termos de uma ação. A visão que ele e outros estudiosos derivam de uma Abordagem existencial fenomenológica estabelece a importância dos aspectos pessoais acima dos contratuais, das atitudes facilitadoras aci- 
ma das técnicas pedagógicas e da experiência vivida acima da informação. Tenta um acordo harmônico entre o que é e o que poderia ser, entre partes e necessidades diferentes do todo: pensamento e experiência, formação $e$ profissão.

A civilização tem avançado, mas certos aprendizados óbvios que nos vêm do social demoram a ser absorvidos pela humanidade e pela teoria científica. Sobre a vida coletiva moderna, Peretti afirma:“Uma enorme tomada de consciência da sociedade proletária revirou. a economia do mundo moderno, abalando os ideais e valores tradicionais" (1972, p. 13). O autor também ressalta que, se por um lado é verdade que hoje as relações de trabalho são as de "força e dominação", por outro lado a tecnologia não representa apenas perigo, pois certamente aliviou a carga do trabalhador. Como tais fatos, tão amplamente conhecidos, recebem ainda tão pouca atenção que precisamos nos lembrar deles?

Mas é preciso dizer que a situação não é tão universal, tão homogênea, como Peretti parece imaginar. Bosi (1972), psicóloga social, nos leva a observar que o que se passa com o trabalhador na França e nos Estados Unidos não se aplica ao Brasil, onde " há o passado rural recente, pouca tradição de luta. ., e o trabalhador de origem rural se identifica com todo pobre (com aquele que trabalha de dia para comer de noite), grupo dos mais heterogêneos do Brasil" (p. 158). No entanto, se a identidade de classe não constitui nos nossos trabalhadores essa característica predominante, "o operário vive realmente, como homem do povo, uma cultura popular, que poderá ser mais ou menos marcada por traços regionais (p. 162) Ela é a única que se realiza na militância, ou se atrofia; e que é sempre engajada, ou não é, quer dizer, não existe" (p. 166).

De autores e realidades tão variáveis, percebe-se bem quão verdadeira a alegação de que fatos sociais não são isolados, nem tão pouco universais, e certamente povoam o domínio da Ciência tanto quanto o dos valores, de modo mais ou menos explícito. Mais ainda, parecemos esquecer quanto muitas vezes co-dependem dos mesmos movimentos econômicos, ideológicos, políticos e tecnológicos. A obrigação ética abrangida pelo exercício da Ciência tem preocupado muito os praticantes e estudiosos de certos ramos da Ciência, notadamente os que se ligam a aplicações bélicas e médicas, mas é evidente a 
falta de comunicação fluída entre os vários níveis do fazer humano Os cientistas do comportamento às vezes manifestam seu desgosto pelo valor pequeno que lhes é dado por governos ou instituições sociais - o social desvalorizando a Ciência. Mas as acusações poderiam ser revertidas, o que não significa necessariamente incompetência da Ciência ou da sociedade. Voltando a Dyson:" a sociedade soviética ., tal como a sociedade ocidental, é regida por pessoas que praticam a arte de governar sem grande ajuda da teoria científica" (1984, p. 58). Na verdade, a teoria científica até muito recentemente pareceu sobretudo evitar qualquer política de aproximação, seja com a Arte seja com as pessoas, e talvez por isso sua afinação com os problemas mais "reais" do mundo seja tão precária.

i A tecnologia forneceu os meios e as armas, tanto para a autodestruição da humanidade, como para a coexistência mais harmoniosa no universo. Como usar esses instrumentos é de fato uma questão ideológica, mas, além disso, de sabedoria. Estará a Ciência disposta e apta a buscar sabedoria, para além do conhecimento?

Algumas respostas afirmativas se propõem à pergunta, com pontos de origem muito distintos, seja encerrados em movimentos alternativos de jovens ou de conscientização, seja em programas estruturados como os da Universidade para a Paz, na Costa Rica (Rogers, 1986). Nas palavras de seu presidente, dr. Carazo, "esta instituição internacional de Educação superior tem por meta promover entre todos os seres humanos um espírito favorável de compreensão, tolerância e coexistência, que estimule a cooperação entre os povos e ajude a reduzir as ameaças à paz e ao progresso mundiais " (1979). Infelizmente, é quase sempre verdade em nossa era que "quando se analisa o mundo da organização humana, a responsabilidade coletiva acarreta um rebaixamento nos padrões morais. Um exemplo extremado se vê na instituição militar" (Dyson, 1984, p. 54). Precisamos de ajuda, mudança e trabalho.

Sobre experiência, intuição e Ciência:

Os experimentos chamados de "comunidades de aprendizagem centradas na pessoa" são processos de grupos intensivos, de curta duração, aos quais se propõe assumir as suas próprias direções, ativi- 
dades, formas de decisão e relação, com a ajuda de facilitadores da plena auto-expressão de cada participante. Estes miniensaios de alternativas psicossociais nos mostram de maneira convincente vários fatos que vêm a ligar-se à questão da paz no coletivo. Por exemplo: "Paradoxalmente, a verdadeira comunidade nasce do desenvolvimento pleno de cada indivíduo que nela se insere" Ou, no mesmo enfoque: "A vida em comunidade tem sido vista, sobretudo, como condição prévia para um convívio mais convergente quando, mais provavelmente, ela só pode ser resultante deste convívio convergido" (Rosenberg, 1981). Concomitantemente, para o autoconhecimento e o desenvolvimento pleno do indivíduo, é necessário vivenciar o Outro, o Grupo, a Sociedade. Dito de outra forma, aprendemos que ser centrado na comunidade não basta para o crescimento social, e tanto constitui efeito como uma causa. Nossa tarefa é a de descobrir, para criar, as condições que tornam as comunidades centradas em cada pessoa. Parece que só então comunidades verdadeiras terão as condições necessárias e suficientes para ser.

Sem dúvida, dizer de tais condições que são suficientes na vida social quotidiana, é uma ousadia ou, no mínimo, uma proposta a ser melhor confirmada. No entanto, é este o tipo de interdependência que começamos a entrever como o terreno para nosso próximo passo na dimensão da sabedoria. John $\mathrm{K}$. Wood, estudioso norte-americano residente no Brasil, sugere que "Talvez do que necessitamos é uma percepção do 'humano' que não se fundamente na individualidade nem na coletividade, e sim se baseie em algo mais essencial" (1982, p. 3). Eu acrescentaria que isto exige, e ao mesmo tempo transcende, a interdependência indivíduo/coletividade.

Nas realidades infinitamente complexas de nosso planeta, nossos países, nossos grupos pessoais, as situações de aprendizagem são nada mais que uma molécula, talvez demais pequena para lograr qualquer efeito significativo. Contudo, algumas situações de aprendizagem são o que nós podemos mudar sabendo que alterações numa única molécula de um organismo podem ser fatores decisivos na mutação - de todo o organismo.

Embora de minhas anotações eu tenha avançado pouco além do que deveria ser a introdução, descubro ter alinhado aqui, em termos nada acadêmicos, o que para minha surpresa são o fundamento e a 
metodologia para qualquer programa de aprendizagem em que eu possa acreditar. Um programa que consista de estar com outros, ouvi-los e a mim mesma toda ouvidos e coração, deixando-nos fluir através de meus próprios pensamentos e emoções. Ao escrever este artigo, senti o companheirismo vivo daqueles de quem li, copiei e aprendi. Agradeço a vocês, minhas caras "referências" (várias com traduções livres), por ter podido ter esta experiência nova e por aprender não somente de, e através de, vocês, mas com a sua presença cúmplice. É como sentarmos juntos, e deixar que a aprendizagem aconteça até que a sabedoria lance nossas mentes e nossas almas para uma consciência mais alta.

A aprendizagem, a formação profissional e o crescimento das pessoas, estas têm sido minha ocupação e preocupação de todo dia por muitos anos. Garcia Márquez, prêmio Nobel, foi quem me mostrou porque me parecia tão difícil escrever sobre assunto tão familiar. Numa entrevista publicada, o escritor colombiano conta de Mercedes, sua esposa:

“Nunca pude ir mais longe em seu aproveitamento literário, por causa de uma verdade que poderia parecer uma boutade, mas não é; vim a conhecê-la tanto que não tenho mais a menor idéia de como ela realmente é" (1983, p. 83).

E eu nada disse sobre a intuição.

\section{BIBLIOGRAFIA}

B LEGER, J. Custiones Metodológicas del Psicoanálisis. In Ziziemsky, D., ed. Métodos de Imvestigación en Psicologia y Psicopatologia, Buenos Aires, Nueva Visión, 1971.

BOSI, E. Cultura de Massa e Cultura Popular: Leituras de Operárias, Petrópolis, Vozes, 1972.

CARAZO, R. Adress to the UN Genetal Assembly, 1979. Folheto da University for Peace, 1983.

DYSON, F. Reflections: Weapons and Hope. The New Yorker, 6, fev., 1984.

FILlOUX. J. Clinique et Pédagogie. Revue Française de Pédagogie, 54, 1983.

GARCIA MÁRQUEZ, G. Cheiro de Goiaba: Conversas com Plinio Apuleyo Mendoza. Rio de Janeiro, Record, 1983.

ILLICH, I. Hacia el Fin de la Vida Escolar, Cuernavaca, CIDOC, 1971.

MASLOW, A. The Farther Reaches of Human Nature, New York, Viking, 1971.

MORENO LÓPEZ, S. La Educación Centrada en la Persona, México, D. F.: El Manual Moderno, 1979. 
PERETTI, A. de Risques et Chances de la Vie Collective, Paris, EPI, 1972.

PRETTO, S. P. N. Educação Humanista, São Paulo, Cortez \& Morais, 1978.

ROGERS, C. R. Liberdade de Aprender na Década Atual, Porto Alegre, Artes, 1985.

ROGERS, C. R. Toward a More Human Science of the Person. J. of Humanistic Psychology, 25, 4, 7-24, Fall 1985 .

ROGERS, C.R. The Rust Workshop: a Personal over View. J. of Humanistic Psychology, 26, 3, 23 - 45, Summer 1986.

ROSENBERG, R. L. Comunhão e Solidariedade. Folha de São Paulo, 8.8.81.

WOOD, J. K. When Two Are Together, You Have a Unity. Trabalho apresentado no I? Forum Internacional da Abordagem Centrada na Pessoa, México, 1982.

Traduzido e adaptado de trabalho apresentado no // International Forum on The Person Centered Approach, em Norwich, Inglaterra, 1984, com apoio da Fapesp.

\section{FICHA CATALOGRÁFICA}

ROSENBERG, Rachel Lea. Aprendizagem Sobre 0 Aprender: $O$ Fio da Sintonia. Revista da Universidade de São Paulo. São Paulo, (4): p. 53 - 64, março de 1987. 